\title{
LA PUBLICIDAD DE LAS SESIONES DE LAS COMISIONES MUNICIPALES PERMANENTES $Y$ EL PRINCIPIO CONSTITUCIONAL DE LA AUTONOMIA MUNICIPAL
}

(Comentario a la sentencia del Tribunal Supremo de 27 de Octubre de 1982)

340.142: 352.072 .1

por

José-Luis López de Turiso Moraza

Secretario general del Excmo. Ayuntamiento de Logroño

SUMARIO: I. PLANTEAMIENTO. - II. LAS CUESTIONES SUSCITADAS EN EL PROCESO Y LAS POSTURAS MANTENIDAS: 1. La SUPERACIÓN DE PLANTEAMIENTOS FORMALISTAS. 2. El NUEVO CARACTER DE LAS COMISIONES MUNICIPALES PERMANENTES Y LA POSIBLE DEROGACIÓN DEL ARTÍCULO 213 DEL ROFRJ. 3. LA DEROGACION DEL ARTÍCULO 213 DEL ROFRJ, EN VIRTUD DEL PRINCIPIO CONSTITUCIONAL DE LA AUTONOMIA MUNICIPAL.-III. CONCLUSION.

\section{PLANTEAMIENTO}

La nueva etapa de la Vida local española, que se inscribe en el proceso de reforma política del Estado, preparada por la Ley de 
Elecciones locales de 17 de julio de 1978 (LEL), inaugurada por la Constitución española e iniciada con la renovación de los Ayuntamientos y Diputaciones, encuentra una de sus mayores dificultades en la permanencia de un Ordenamiento jurídico local fragmentario, asistemático, contradictorio e incompatible con la realidad social, política y administrativa en que las Entidades locales han de desenvolverse; se ha hablado al respecto de un estado de anomia $\mathrm{y}$, en verdad, el familiar conjunto normativo constituido por una sola Ley y seis Reglamentos se ve hoy día fragmentado en una buena docena de normas con rango de Ley y en un número de disposiciones reglamentarias que se resiste a cualquier cómputo. En estas circunstancias la práctica administrativa se hace dificultosa; surgen cuestiones más propias de planteamientos doctrinales, legales o políticos; $\mathrm{y}$, como consecuencia, la actuación cotidiana se carga de complejidad, exige un esfuerzo desproporcionado a la importancia del tema que la suscita, adolece con frecuencia de inseguridad y falta de convicción y causa desilusión y exasperación en los órganos representativos con poder decisorio.

La publicidad de las sesiones de la Comisión municipal permanente constituye un ejemplo típico de lo que acabamos de exponer. Por una parte, un texto reglamentario del año 1952, el Reglamento de Organización, Funcionamiento y Régimen jurídico de las Corporaciones locales (ROFRJ), proclama de forma tajante que dichas sesiones «no serán públicas» (art. 213); pero, por otra, una norma con rango de Ley, la Ley de Elecciones locales, en el apartado 5 del artículo 28 (precepto de un contenido muy heterogéneo que regula la sesión constitutiva de los nuevos Ayuntamientos, la elección del Alcalde, la composición de la Comisión municipal permanente y la adscripción de sus puestos a las distintas listas), establece genéricamente y sin la más mínima concreción que «las sesiones serán públicas».

La cuestión, como se deduce de este simple y escueto planteamiento, presenta dudas y se presta a posturas dispares, tanto juridicas como políticas.

Fueron numerosos los Ayuntamientos, a raíz de la renovación de las Corporaciones locales, que espontáneamente, y al margen de cualquier decisión formal, comenzaron a celebrar públicamente las sesiones de la Comisión municipal permanente.

Sin embargo, la Resolución de la Dirección General de Administración Local de 25 de mayo de 1979 (Boletín Oficial del Estado del día 30) vino a sentar una serie de criterios interpretativos sobre la 
normativa vigente en materia de funcionamiento de las Corporaciones locales, afirmando sin el más mínimo razonamiento que el «artículo 28, 5, de la Ley de Elecciones locales, al establecer que 'las sesiones serán públicas', se está refiriendo exclusivamente a las sesiones de constitución de las Corporaciones locales» (al margen del tema, resulta sorprendente la ausencia de fundamentación de la Resolución, pues una disposición cuyo carácter no es imperativo, sino puramente interpretativo, deriva únicamente su fuerza de la bondad de los criterios en que se apoyan y que paradójicamente silencia).

Y, poco tiempo después, el Consejo de Estado, en un Dictamen del año 1979, vino a sentar la doctrina «que las sesiones de las Comisiones permanentes de los Ayuntamientos y de Gobierno de las Diputaciones no tienen legalmente carácter público». El Dictamen, tras reproducir los artículos 296 de la LRL y 213 del ROFRJ, afirma que:

«No parece, por tanto, que deba existir duda en cuanto a la no publicidad de las sesiones de dichas Comisiones, así taxativamente establecidad.

«Tal es el temor de la legislación vigente, independientemente de las consideraciones que, de lege ferenda, pudieran hacerse en favor de una u otra solución. Y hay que entender que ese conjunto de normas no fue modificado por la Ley de Elecciones locales, pues no fue éste su propósito, y el pronunciamiento de su artículo 28,5 , relativo a la publicidad, ha de considerarse referido a las sesiones constitutivas, pues es el objeto de la Ley, que para nada se propuso modificar la legislación vigente en materias distintas de las específicas que abarca».

La tesis favorable a la no publicidad de las sesiones de la Comisión municipal permanente parecía, pues, prácticamente consagrada; aunque en forma no enteramente satisfactoria, ya que o bien no se exteriorizaban los argumentos, o bien éstos se circunscribían a la pura antinomia entre la LEL y el ROFRJ, eludiendo abiertamente una serie de cuestiones inmersas directamente en el tema.

De ahí la importancia de la sentencia de la Sala Cuarta del Tribunal Supremo de 26 de octubre de 1982 -Ponente, excelentísimo seños Santolaya SánCHEZ-, que no sólo revive el problema, sino que lo analiza con profundidad en su total dimensión y sienta una postura de gran trascendencia para la autonomía municipal.

El supuesto de hecho fue el siguiente: el Ayuntamiento de Logroño, en la sesión plenaria de 19 de mayo de 1979, adoptó el acuerdo de «declarar públicas las sesiones que celebre la Comisión municipal 
permanente», aceptando el informe del Secretario general de 9 de mayo de 1979, cuyas conclusiones eran las siguientes:

«Primera: Dados los principios que inspiran la Constitución española, el sentido a que responde la publicidad de las sesiones de los órganos colegiados municipales y la naturaleza que a las Comisiones municipales permanentes atribuye la Ley de Elecciones locales, la no publicidad establecida por el Reglamento de Organización, Funcionamiento y Régimen jurídico de las Corpo raciones locales no puede estimarse vigente en el momento actual. Segunda: Con independencia de lo anterior, existen fundamentos jurídicos suficientes para afirmar que el párrafo quinto del artículo 28 de la Ley de Elecciones locales sienta el principio de publicidad de las sesiones de la Comisión municipal permanente y deroga, en consecuencia, el artículo 213 del ROFRJ».

El acuerdo municipal fue suspendido por el Gobierno civil de la Provincia. Dado traslado a la Sala de lo Contencioso-administrativo de la Audiencia Territorial de Burgos, ésta, por sentencia de 29 de noviembre de 1979, confirma la suspensión y declara nulo y sin efecto alguno el acuerdo municipal. Apelada la sentencia por el Ayuntamiento, la Sala Cuarta del Tribunal Supremo, en la sentencia de 27 de octubre de 1982, objeto del presente comentario, revoca la del Tribunal de instancia y levanta la suspensión del acuerdo municipal. Pero lo fundamental son las posturas mantenidas sobre las distintas cuestiones por los diversos actores en este largo proceso: Ayuntamiento, Administración del Estado y órganos jurisdiccionales.

\section{LAS CUESTIONES SUSCITADAS EN EL PROCESO Y LAS POSTURAS MANTENIDAS}

\section{LA SUPERACIÓN DE PLANTEAMIENTOS FORMALISTAS}

Esta es la postura que insistentemente mantiene el Ayuntamiento de Logroño en sus actuaciones respecto al tema objeto del recurso:

«La cuestión de la publicidad de las sesiones de la Comisión municipal permanente ha de abordarse hoy desde perspectivas muy distintas a las exclusivamente formales... el Ordenamiento jurídico del momento actual, máxime en el campo del Derecho público y administrativo, no constituye un conjunto unitario y sistemático; el proceso de reforma política está introduciendo en el mismo cambios muy sustanciales, que no se reducen simplemente al ele- 
mento afectado, sino que, en mayor o menor medida, repercute en todo el conjunto, implicando una reestructuración del mismo».

«(Postular) que el párrafo quinto del artículo 28 se está refiriendo tan sólo a la publicidad de las sesiones constitutivas de los nuevos Ayuntamientos responde a un criterio interpretativo formalista e insuficiente, muy alejado de las pautas que para la interpretación jurídica postula el artículo 3.० del Código civil y de la indispensable visión completiva y sistémica del Ordenamiento jurídico...» (Alegación ante el Tribunal de instancia de 23 de junio de 1979).

De ahí que la postura municipal invoque reiteradamente la necesidad de tener en cuenta elementos tales como los principios que inspiran la Constitución española; el principio de autonomía que el Texto constitucional no sólo proclama, sino que además garantiza; los criterios que están inspirando la reforma política; el talante democrático consustancial al Régimen local; el sentido a que obedece la publicidad de las sesiones de los órganos colegiados; la nueva naturaleza y significación que a las Comisiones municipales permanentes atribuye la LEL; etcétera.

Frente a esta postura, el Gobierno civil reduce el tema de la publicidad de la Comisión municipal permanente a la simple contradicción entre el artículo 213 del ROFRJ y el 28, 5, de la LEL, contradicción que analiza y valora exclusivamente desde la pura literalidad de ambos preceptos. Este es también el criterio de la Resolución de la Dirección General de Administración Local de 25 de mayo de 1979; y del Dictamen del Consejo de Estado de 1979, que relega los aspectos señalados a "cuestiones de lege ferenda»; y, asimismo, el de la sentencia apelada, para la que las normas sobre la publicidad de las sesiones

"se limitan a cuestiones de procedimiento"; (y) «el régimen establecido en este punto será susceptible de distintas valoraciones en su aspecto político -que no corresponde hacer a esta Sala-, pero en tanto no sea modificado debe acatarse».

Por el contrario, la doctrina de la sentencia del Tribunal Supremo que comentamos es radicalmente distinta y viene a afirmar en su considerando segundo

"Que el tema que en esta apelación se somete a la decisión de la Sala, que en definitiva se concreta en la posibilidad de la publicidad de las sesiones que celebre la Comisión municipal permanente de un Ayuntamiento, no puede ser 
enfocado desde las perspectivas de un puro formalismo jurídico, porque, debiendo interpretarse las normas jurídicas, según ordena el artículo $3 .^{\circ}, 1$, del Código civil, según el sentido propio de sus palabras, en relación con el contexto, los antecedentes históricos y legislativos y la realidad social del tiempo en que han de ser aplicadas, nos impone enjuiciarlo en contemplación del proceso de reforma desarrollado en nuestra Patria, que iniciado en la Ley de Reforma política de 4 de enero de 1977, culmina en la Constitución española de 1978 , proceso que nos pone de manifiesto nuestra actual realidad social y las sustanciales transformaciones y democratización operadas en nuestras estructuras político-administrativas, que necesariamente hemos de tomar en consideración, máxime cuando a través del Real Decreto número 1710, de 16 de julio de 1979, por el que se deja sin efecto procedimientos de fiscalización, intervención y tutela del Ministerio de Administración Territorial sobre Entidades locales en diversas materias, en su exposición de motivos literalmente se dice: 'La Constitución que en el ejercicio de su soberanía se ha dado la Nación española ha decidido que las Entidades locales gozan de autonomía para la gestión de sus intereses, por lo que el Gobierno debe suprimir todos aquellos procedimientos de fiscalización que no sean absolutamente necesarios para asegurar la coordinación entre las actuaciones de los órganos estatales y los de las Corporaciones locales', de cuya declaración la conclusión que se tiene que sacar es la que es el propio Poder ejecutivo el que estima que son improcedentes todas aquellas suspensiones que tengan por objeto acuerdos municipales que no sean aptos, por sí mismos, de perturbar o hacer quebrar la necesaria y obligada coordinación de actuación de la Administración central y de la Administración local».

\section{El NUEVO CARÁCTER DE LAS COMISIONES MUNICIPALES PERMANENTES Y LA POSIBLE DEROGACIÓN DEL ARTÍCULO 213 DEL ROFRJ}

Es importante, a pesar de no haber sido suficientemente destacado, el nuevo carácter que adquieren las Comisiones municipales permanentes de los Ayuntamientos como consecuencia de la LEL y su contraste con el que ofrecían en el sistema surgido de la Ley de Bases de Régimen local de 1945.

Dichas Comisiones, creadas por el Estatuto Municipal de 1924 y mantenidas por la Ley Municipal de 1935, como órganos colegiados de descongestión funcional del Ayuntamiento pleno, se configuran, no obstante, por la LRL, bajo unas pautas más próximas al Alcalde que al propio Ayuntamiento pleno, pues es el Alcalde quien, además de presidirla, configura realmente dicha Comisión. Así, concreta su com- 
posición numérica dentro de ciertos límites (supuesto normal, igual al número de Distritos, y supuesto máximo, la mitad del número legal de Concejales); al estar compuesta por los Tenientes de Alcalde, y ser éstos designados por el Alcalde, es él quien decide la composición individual de la Comisión; al poder remover libremente a los Tenientes de Alcalde puede alterar en cualquier momento la composición de la Comisión y tiene asegurada en buena medida su fidelidad; confirma asimismo esta vinculación de la Comisión municipal permanente al Alcalde la posibilidad legal de delegación de funciones de la primera en el segundo (art. 116, $i, \mathrm{LRL}$ ).

La postura municipal destaca la innovación que en cuanto a la estructura orgánica de las Entidades locales ha supuesto la LEL, Ley que

a... trasciende el puro aspecto electoral... Es, tanto o más que una Ley de Elecciones, una norma que, partiendo de los principios que vienen informando el proceso de cambio político, reforma drásticamente la estructura orgánica de la Administración local española».

Ley en la que la Comisión municipal permanente

«... es objeto de una profunda reforma por el artículo citado y adquiere un carácter radicalmente distinto al derivado de la Ley de Régimen local. Así, se amplía su composición numérica; se integra por Concejales y no por Tenientes de Alcalde; se elige por el Ayuntamiento y no por el Alcalde; y su composición refleja proporcionalmente las tendencias políticas que concurren en el Ayuntamiento pleno y no el criterio del Alcalde. En realidad, la Comisión municipal permanente se convierte en una reproducción a escala reducida del Ayuntamiento pleno» (Alegación ante el Tribunal de instancia).

De ahí que el Ayuntamiento sostenga que este nuevo carácter de la Comisión municipal permanente, juntamente con los principios de democratización de las instituciones y de la vida pública y de la autonomía municipal, son suficientes para determinar, dado el rango de las disposiciones en que se plasman, la pérdida de vigencia del artículo 213 del ROFRJ.

La sentencia del Tribunal Supremo recoge el cambio de naturaleza operado por la Comisión municipal permanente en su considerando tercero: 
aConsiderando: Que frente al principio de publicidad de las sesiones del Ayuntamiento pleno que con limitadas restricciones establece el artículo 296 de la Ley de Régimen local, el artículo 213 del Reglamento de Organización, Funcionamiento y Régimen jurídico de las Corporaciones locales declara que las sesiones de la Comisión municipal permanente no serán públicas; pero esta norma reglamentaria dictada para regular el régimen jurídico de un organo de un Ayuntamiento inspirado y regido por criterios doctrinales y politicos sustancialmente distintos de los que inspiran a los nuevos Ayuntamientos surgidos después de la Ley de Reforma política, hay que ponerla en relación con la Ley de Elecciones municipales de 17 de julio de 1978, que indiscutiblemente contiene previsiones que pueden considerarse atípicas de una pura Ley Electoral, pues, rebasando su propio enunciado, no sólo contiene las normas que van a regir la elección de los miembros de las nuevas Corporaciones locales, sino que, respondiendo a la distinta filosofía política que la inspira, introduce principios de organización local que pugnan con la legislación local vigente, y así, en su artículo 28 , lleva a cabo una profunda y sustancial reforma de los órganos de la Administración local en lo relativo a la composición del Ayuntamiento pleno, elección de Alcalde y carácter de este cargo, y de su Comisión municipal permanente, para enmarcarlas en el nuevo marco político, presentándonos una Comisión municipal desvinculada del Alcalde que se limita a presidirla, con una composición numérica que se fija objetivamente y se corresponde proporcionalmente con las tendencias políticas que concurren en el Ayuntamiento pleno, y que sus componentes, que no adquieren la condición de Tenientes de Alcalde, son elegidos por la Corporación y no por el Alcalde; estableciéndose en el número 5 del expresado artículo escuetamente 'que las sesiones serán públicas'».

Pero sin entrar a pronunciarse acerca de si este cambio de naturaleza, justamente con los principios a que responde, es suficiente para postular la derogación del artículo 213 del ROFRJ.

"CONSIDERANDo: Que sin entrar en la decisión, por no ser ello necesario, por lo que más adelante razonaremos, de si esta declaración de publicidad de las sesiones que el artículo 28 de la Ley Electoral citada hace se refiere a la sesión del Ayuntamiento pleno constituyente de la Corporación local elegida, tesis que sostiene el Abogado del Estado y comparte la sentencia apelada, o, por el contrario, si dicha publicidad se dispone para las sesiones que una vez constituida la nueva Corporación celebren tanto el Ayuntamiento pleno como la Comisión municipal permanente, con lo que ese apartado 5 tiene un claro y justificado sentido innovatorio, concorde con el carácter asignado a estos brganos municipales, con los principios que están inspirando la reforma política y con el carácter democrático consustancial a la Administración local, que es lo que se sostiene por el Ayuntamiento apelante...» (Considerando cuarto). 


\section{LA DEROGACIÓN DEL ARTícUlo 213 DEL ROFRJ, EN VIRTUD DEL PRINCIPIO CONSTITUCIONAL DE LA AUTONOMIA MUNICIPAL}

Es, sin duda alguna, la aportación más fundamental de la sentencia. El Ayuntamiento de Logroño había planteado el argumento en la alegación ante el Tribunal de instancia, bajo los siguientes términos:

«La derogación del artículo 213 del Reglamento se produce asimismo en virtud de la operatividad del principio de autonomía de los Municipios que la Constitución española establece y garantiza en los artículos 137 y 140, con expresa derogación de cuantas disposiciones se opongan al mismo (Disposición derogatoria, apartado tres). En virtud de este principio, el Municipio ostenta potestad para regular la organización y funcionamiento de sus órganos de gobierno con arreglo a la Ley, pero sin que puedan implicar limitación al ejercicio de la misma las disposiciones reglamentarias del Poder ejecutivo».

Este argumento está extraído directamente de la tesis defendida por el malogrado GARCIA-TREVIJANo Fos, como expresamente destaca la alegación municipal:

«Esta postura, realmente incomprensible desde los postulados del pasado régimen político, resulta en la actualidad obligada sin el más mínimo reparo, pues obedece a un sólido fundamento unánimemente aceptado en otros países y proclamado en el nuestro por la doctrina administrativa. Garcfa-TreviJano Fos, al examinar la conexión entre la potestad normativa estatal y la autonomía, sienta las siguientes conclusiones: ' $a$ ) Si la Constitución defiende la autonomía, ni siquiera la Ley puede limitarla arbitrariamente, pero sí delimitarla. b) Si no hay tal defensa, la Ley no tiene límites, pero sí los actos del Ejecutivo' (Tratado de Derecho administrativo, tomo II, 1967, pág. 453)».

Pues bien: la sentencia que comentamos analiza el principio de autonomía y su repercusión respecto a la declaración municipal sobre la publicidad de las sesiones de la Comisión municipal permanente en sus considerandos cuarto, quinto y sexto, afirmando:

«Considerando: Que... sí hemos de tener muy presente que la Constitución española, al tratar en su Título VIII de la organización territorial del Estado, declara en su artículo 137, tras enumerar los Entes a través de los cuales el Estado se organiza - Municipios, Provincias y Comunidades Autónomas-, que 'todas estas Entidades gozan de autonomía para la gestión de sus respectivos intereses', autonomía que, en lo que hace referencia a los Entes locales, tiene el alcance y significado de dejar establecida su sustantividad y plena persona- 
lidad jurídica para el cumplimiento de sus fines; extremo en el que se insiste, respecto de los Municipios, cuando en el artículo 140 declara que la Constitución garantiza la autonomía de los Municipios, que éstos gozarán de personalidad jurídica plena y que su gobierno y administración corresponde a sus respectivos Ayuntamientos integrados por los Alcaldes y Concejales.

CONSIDERANDo: Que la Constitución es, esencialmente, una norma jurídica parámetro de validez de todas las demás normas del Ordenamiento y a la vez determinante de toda su interpretación y aplicación, y esto es significativamente cierto en el caso de preceptos constitucionales organizadores de los poderes públicos, como lo son, en grado eminente, los preceptos que integran su Título VIII, que, por tal razón, resulta de inequívoca aplicación directa, con efecto normativo inmediato, sin que su eficacia esté condicionada a normas que le desarrollen; y teniendo los Municipios por la autonomía para la gestión de sus respectivos intereses a que antes hemos aludido, potestad para regular la organización y funcionamiento de sus órganos de gobierno en el marco del Ordenamiento, es lo cierto que esta autonomía que la Constitución otorga a los Entes territoriales en que el Estado se organiza, como tiene declarado el Tribunal Constitucional en su sentencia de 2 de febrero de 1981, es compatible, como consecuencia del principio de unidad y de la supremacía del interés de la Nación, con que el Estado quede colocado en una posición de superioridad y la existencia de un control de legalidad sobre el ejercicio que aquéllos hacen de sus competencias, sin que ello quiera decir que se le conceda la previsión de controles genéricos e indeterminados que siguen a las Entidades locales en una posición de subordinación o dependencia jerárquica de la Administración del Estado, ya que, en todo caso, los controles habrán de limitarse, normalmente, a supuestos en los que el ejercicio de las compe. tencias de la Entidad local incidan en intereses generales concurrentes con los propios de la Entidad, control de legalidad que, con la precisión anterior, puede ejercerse en el caso de los Municipios y Provincias por la Administración del Estado y, naturalmente, siempre con la posibilidad de control jurisdiccional posterior; de lo que necesariamente se ha de deducir que esa autonomía que la suprema norma - Constitución- les reconoce y garantiza a los Municipios no puede ser limitada por una simple norma de carácter reglamentario que, además, repugna a la democratización de la vida pública local, a la naturaleza y función de los nuevos Ayuntamientos y a la legitimación representativa de las actuales Corporaciones locales.

CoNSIDERANDO: Que por lo que razonado queda, necesario es concluir que la no publicidad de las sesiones a celebrar por las Comisiones municipales permanentes, establecida por el artículo 213 del Reglamento de Organización, Funcionamiento y Régimen jurídico de las Corporaciones locales, se opone abiertamente al principio de autonomía que para la gestión de sus respectivos intereses otorga a los Ayuntamientos la Constitución española, y aunque, como declara la sentencia del Tribunal Constitucional citada, así como frente a las Leyes postconstitucionales corresponde exclusivamente a dicho Tribunal enjuiciar su conformidad con la Constitución, en relación con las preconstitucionales, los Jueces y Tribunales deben inaplicarlas si entienden que han que- 
dado derogadas por la Constitución al oponerse a la misma; supuesto ante el que, evidentemente, nos encontramos, y que necesariamente nos lleva con la estimación del recurso de apelación interpuesto a la revocación de la sentencia dictada, levantando la suspensión decretada por el Gobernador civil de Logroño del Acuerdo del Ayuntamiento pleno de dicha capital de 19 de mayo de 1979, que declaró públicas las sesiones que celebre la Comisión municipal permanente».

La importancia de la sentencia en este punto es fundamental. Aparte de afectar positivamente a la autonomía municipal, empequeñecida y relegada por la de las Nacionalidades y Regiones (es significativo que se haya conmemorado el cuarto aniversario de la Constitución española sin haberse promulgado aún la Ley de Régimen local), y de derivar directamente de su consagración constitucional la derogación del artículo 213 del ROFRJ, se centra en un aspecto sustancial de la autonomía, como es el relativo a la incidencia de la potestad reglamentaria estatal sobre la organización, funcionamiento $\mathrm{y}$ actividad de las Corporaciones locales. Potestad que el Gobierno y la Administración del Estado han venido ejerciendo tradicionalmente con especial fruición y que, no obstante la declaración constitucional de la autonomía municipal, continúan aún desarrollando, como puede comprobarse diariamente en el Boletín Oficial del Estado; aspecto en el que existe un vacío legal, no cubierto con elaboraciones doctrinales y jurisprudenciales, y que por su propia naturaleza de disposición sin rango de Ley está exento de la garantía que el Tribunal Constitucional ejerce sobre el primado de la Constitución.

\section{CONCLUSION}

Estimamos que la sentencia del Tribunal Supremo de 27 de octubre de 1982 y el Ayuntamiento de Logroño -que con sus actuaciones la ha propiciado- han dado un paso importante en la construcción de la difícil autonomía municipal; un paso dado, al margen de enfáticas declaraciones al uso, en el plano operativo y real, que es el que, en definitiva, sirve para valorar el grado efectivo de dicha autonomía, pues, como señala S. MARTín RETORTILlo, 
«Es así como, desde esta visión microscópica y particularizada, se sitúa el tema (de la autonomía) en una tensión constante, eminentemente dinámica, de avance o de retroceso. Una tensión que se ejerce no sobre términos o ideas abstractas, sino sobre posibilidades sectoriales particulares, fiscalizables por los Tribunales, y que son los que, en definitiva, determinan las efectivas funciones reales de las distintas Administraciones locales y, consecuentemente, el ámbito efectivo de esa autonomía, cuyo marco puede estar normativamente reconocidos (Descentralización administrativa y organización política, tomo I,

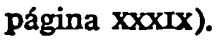

